\title{
Comparison of embryo recovery, embryo quality, oestradiol-17ß and progesterone profiles in domestic cats (Felis catus) at natural or induced oestrus
}

\author{
K. L. Goodrowe*†, J. G. Howard* and D. E. Wildt* \\ *National Zoological Park, Smithsonian Institution, Washington, DC 20008, and \\ $\uparrow$ Department of Physiology, Uniformed Services University, Bethesda, MD 20814, U.S.A.
}

\begin{abstract}
Summary. Domestic cats experiencing a natural or FSH-induced oestrus were studied. Mated cats produced fewer $(P<0.01)$ unfertilized oocytes and more $(P<0.01)$ morulato blastocyst-stage embryos of better quality after a natural oestrus than after FSH treatment. Serum oestradiol-17 $\beta$ concentrations were lower $(P<0.05)$ and progesterone levels rose earlier $(P<0.05)$ in the induced oestrus compared to the natural oestrus group. Morula/blastocyst-stage embryos from both groups transferred to $15 \mathrm{FSH} / \mathrm{hCG}$ treated recipients produced 3 pregnancies and 2 live-born litters ( 1 from a natural oestrus donor and 1 from an FSH-treated donor). These results indicate that fertilization rates and embryo quality in domestic cats appear to be compromised by the FSH treatment, probably because of altered oestradiol-17 $\beta$ and progesterone concentrations.
\end{abstract}

Keywords: domestic cat; embryo recovery; oestrus; FSH; oestradiol-17ß; progesterone.

\section{Introduction}

Embryo transfer research has contributed markedly to our knowledge of embryogenesis, infertility and the potential for enhancing reproductive efficiency. Little is known about developmental biology in carnivores, including cats. There are 37 existing species of Felidae playing an important role in world ecology and biomedical research; however, the reproductive physiology of this family is poorly understood. In our laboratory, the domestic cat serves as a model for reproductive studies of wild felids (Wild et al., 1986). Although basic ovarian/endocrine relationships have been established for domestic cats (Shille \& Stabenfeldt, 1979; Shille et al., 1979, 1983; Concannon et al., 1980; Wildt et al., 1980, 1981a; Johnson \& Gay, 1981a, b; Banks \& Stabenfeldt, 1982; Schmidt et al., 1983; Glover et al., 1985), only limited information is available concerning the use of exogenous gonadotrophins for inducing ovarian activity (Colby, 1970; Wildt et al., 1978; Cline et al., 1980) and the influence of hormonal preparations on embryonic development and the efficacy of embryo transfer. Successful intra-species transfer of cat embryos has been reported by Kraemer et al. (1979), who used donors and recipients in natural oestrus; 4 pregnancies and 3 live-born litters resulted.

If embryo transfer is ever to have practical application as an approach for enhancing propagation in other species of Felidae with poor breeding records, exogenous gonadotrophins will be required to stimulate ovarian activity in embryo donors and, more importantly, achieve synchrony with embryo recipients. The present study examined the influence of exogenous gonadotrophins on fertilization, embryonic development and the efficiency of embryo transfer in the domestic cat.

\section{Materials and Methods}

Animals. Adult domestic cats were housed alone (males) or in groups of 2-3 (females) and provided with a commercial dry cat food (Purina Cat Chow, St Louis, MO) and water ad libitum. A total of $12 \mathrm{~h}$ of fluorescent light 
was provided daily, but because the colony rooms contained windows, cats were also exposed to natural fluctuations in daylength.

Ovulation induction, embryo collection and transfer. Female cats were assigned to 1 of 2 treatment groups: (1) natural oestrus (Group $N, N=29$ ) or (2) induced oestrus (Group I, $N=30$ ). At I day before gonadotrophin treatment (Day -6), the ovaries of queens in Group I were evaluated by laparoscopy (Wildt, 1980). A surgical plane of anaesthesia was induced with a ketamine $\mathrm{HCl}$ (Vetalar: Parke-Davis, Morris Plains, NJ)/acepromazine maleate (Ayerst Labs, Rouses Pt, NY) mixture (10:1 ratio, $20.0 \mathrm{mg} / \mathrm{kg}$ and $2.0 \mathrm{mg} / \mathrm{kg}$ body wt, respectively, given i.m.). A pneumoperitoneum was established with $100 \% \mathrm{CO}_{2}$ and the ovaries were observed using a 5 -mm diameter laparoscope placed midventrally through a previously inserted trocar-cannula unit. A graduated Verres needle probe was used to manipulate the reproductive organs into view and aid in estimating ovarian follicle size.

Only females with inactive ovaries (no follicles or corpora lutea, CL) or with follicles $<2 \mathrm{~mm}$ in diameter were designated for hormonal treatment (Group I). These cats received $2.0 \mathrm{mg}$ FSH (FSH-P: porcine pituitary extract, Burns-Biotec, Lincoln, NE) i.m. once daily for 5 days (Days -5 through -1 ), a regimen shown to be effective for inducing oestrus and ovarian activity in anoestrous queens (Wildt et al., 1978). Usually, FSH-injected queens are in oestrus within 5-6 days after treatment onset (Wildt, 1986). Females in Group $N$ were monitored daily for signs of oestrous behaviour (i.e. increased vocalization, rubbing, lordosis and treading of the hind legs when exposed to a male; Michael, 1961; Wildt et al., 1978; Shille et al., 1979). Beginning on the first day of oestrus, donor females in Groups I and $N$ were allowed single copulations with intact males 3 times/day with a $3-4 \mathrm{~h}$ interval between each mating for 3 days (Days 1-3). All animals scheduled to receive embryos (recipients) received the same gonadotrophin regimen as cats in Group I. To synchronize ovulation with donor females, embryo recipients were injected with 250 i.u. hCG (Sigma Chemical Co., St Louis, MO) i.m. at 12:00 h on Days 2 and 3 of oestrus.

To confirm ovulation and count CL, donor queens were subjected to a second laparoscopy on Day 4 or 5 . At this time, uterine tone (based on uterine horn morphology) was assessed on a subjective scale of $1-4: 1=$ turgid, enlarged diameter, distinct segmental swellings; 2 = turgid, enlarged, segmental swellings less prominent; $3=$ slight turgidity, no segmental swellings; 4 = flaccid, small diameter, smooth appearance.

For embryo collections, a surgical plane of anaesthesia was induced on Day 7 or 8 with ketamine $\mathrm{HCl} / \mathrm{acepromazine,}$ the animal intubated and maintained with 1-2\% halothane gas. With the reproductive organs exposed at laparotomy, a flanged tomcat catheter was inserted into the caudal terminus of the uterine lumen $(2-3 \mathrm{~cm}$ cranial to the uterine bifurcation). After placing a 17-gauge catheter into the uterine lumen near the utero-tubal junction, 25-30 ml of warmed $\left(37^{\circ} \mathrm{C}\right)$ Ham's F-10 medium (National Institutes of Health Media Unit, Bethesda, MD, U.S.A.) containing $5 \%$ heat inactivated fetal calf serum was flushed normograde (cranial to caudal end) through each uterine horn and collected into $12 \mathrm{ml}(60 \times 15 \mathrm{~mm})$ gridded, plastic tissue culture dishes. The dishes were searched with a stereomicroscope $(\times 12)$ and all embryos and unfertilized eggs were transferred into fresh medium. Each embryo was assessed for developmental stage and assigned a subjective quality grade (1-4) based on morphological appearance (Elsden et al., 1978; Schiewe et al., 1987): 1 = excellent: embryo symmetrical with blastomeres of uniform size and shape; $2=$ good: embryo containing slight imperfections such as a few extruded blastomeres, vesicles or an irregular shape; $3=$ fair: embryo irregularly shaped, blastomeres non-uniform in size and shape, numerous extrusions; $4=$ poor or degenerate: embryo containing numerous extrusions and/or degenerate cells, blastomeres irregular in colour and vesiculated.

After embryo collection and quality grading, a recipient female was anaesthetized and the uterine horns exposed at laparotomy. Using a tomcat catheter attached to a $1 \mathrm{ml}$ syringe, embryos were drawn into $10 \mu \mathrm{l} \mathrm{Ham}$ 's F-10 medium, which was surrounded on both sides by $5 \mu \mathrm{l}$ of air and medium, respectively, to avoid accidental loss of embryos. After puncturing the cranial portion of the uterine horn with a 17-gauge catheter, the contents of the tomcat catheter were expelled into the uterus. Pregnancy was diagnosed at 35 days by abdominal palpation, and pregnant queens were allowed to carry kittens to term.

Endocrine profiles. To determine circulating oestradiol-17 $\beta$ and progesterone patterns in both groups, blood samples $(3 \mathrm{ml}$ ) were collected from random embryo donors by jugular puncture twice daily (at $\sim 08: 30$ and 16:00 h). For Group I females $(N=8)$, samples were collected on Days -6 through Day 6; Group $N$ animals $(N=9)$ were sampled from the first day of oestrus through Day 6 . After centrifugation, sera were recovered and stored at $-20^{\circ} \mathrm{C}$ until assayed. Analysis of oestradiol- $17 \beta$ and progesterone from unextracted sera was performed using commercially available ${ }^{125}$ I double-antibody radioimmunoassay kits (Radioassay Systems, Inc., Carson, CA).

The first and second (in the form of a precipitating solution) antibodies for the oestradiol-17 $\beta$ assay were rabbit 6-keto-oestradiol-17 $\beta$-6-oxime-BSA and goat anti-rabbit gamma globulin, respectively, and detected bound and free unconjugated forms of oestradiol-17 $\beta$. The cross-reactivities of the first antibody were: oestradiol-17 $\beta, 100 \%$; oestrone, $20.0 \%$; oestriol, $1.51 \%$; oestradiol- $17 \alpha, 0.68 \%$; ethinyl oestradiol, testosterone, $5 \alpha$-dihydrotestosterone, cholesterol,

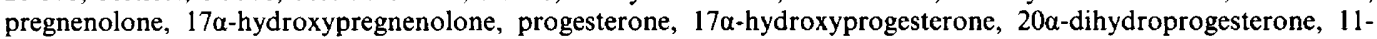
desoxycortisol, cortisol, aldosterone, androstendione, dihydroepiandrosterone and dihydroepiandrosterone sulphate, $<0.01 \%$. Incubation time of the serum with the first antibody and radiolabelled oestradiol-17ß was 90 min. After addition of the precipitating solution, the samples were centrifuged at $2500 \mathrm{~g}$ for $20 \mathrm{~min}$, the supernatant discarded, and the radioactivity in the pellets was quantified with gamma spectrometry. The minimum and maximum detectable levels were 10 and $3000 \mathrm{pg} / \mathrm{ml}$, respectively. After the addition of $100 \mu \mathrm{l}$ of pooled serum to $10,30,100,300,1000$ and $3000 \mathrm{pg}$ oestradiol-17 $, 74 \cdot 4,127 \cdot 9,249 \cdot 6,598 \cdot 6,2156 \cdot 2$ and $3375 \cdot 6 \mathrm{pg}$ oestradiol-17 $\beta$ were recovered following subtraction of endogenous hormone $(r=0.95, P<0.01)$. Inter- and intra-assay coefficients of variation were $6.6 \%$ $(n=6)$ and $3 \cdot 2 \%(n=6)$, respectively. 
The first and second (in the form of a precipitating solution) antibodies for the progesterone assay were rabbit $11 \alpha$ hydroxyprogesterone- $11 \alpha$-hemisuccinate-human serum albumin and goat anti-rabbit gamma globulin, respectively. The reported cross-reactivities of the first antibody were: progesterone, $100 \% ; 20 \alpha$-dihydroprogesterone, $6.25 \%$; desoxycorticosterone, $3.20 \%$; corticosterone, $0.42 \% ; 17 \alpha$-hydroxyprogesterone, $0 \cdot 15 \%$; pregnenolone, $0.06 \%$; androstendione, $0.04 \%$; testosterone, $0.03 \%$; 11 -desoxycortisone, pregnenolone sulphate, cholesterol, dihydroepiandrosterone, etiocholanolone, oestradiol-17 $\beta$, oestradiol-17 $\alpha$, oestrone, oestriol, androsterone, aldosterone and cortisol, $<0.01 \%$. After a $60 \mathrm{~min}$ incubation of the serum with the radiolabelled progesterone and first antibody, the second antibody was added, the samples were centrifuged for $20 \mathrm{~min}$ at $2500 \mathrm{~g}$, the supernatants were decanted and the radioactivity in the remaining pellet was quantified by gamma spectrometry. The minimum and maximum detectable levels of progesterone for this assay were 0.2 and $50.0 \mathrm{ng} / \mathrm{ml}$, respectively. Following the addition of $0.2,0.5,2,5,10$, 25 and $40 \mathrm{ng}$ progesterone to $100 \mu \mathrm{l}$ of pooled serum, and subtraction of endogenous hormone, $0 \cdot 5,0 \cdot 7,3 \cdot 0,7 \cdot 0,14 \cdot 1$, 34.9 and $62.5 \mathrm{ng}$ progesterone were recovered $(r=0.99, P<0.001)$. Inter- and intra-assay coefficients of variation were $12 \cdot 4 \%(n=4)$ and $7 \cdot 0 \%(n=8)$, respectively.

Analysis of data. The mean number of CL and anovulatory follicles/female and the number of embryos plus unfertilized eggs/female producing embryos in Groups $N$ and I were compared using a Student's $t$ test evaluation (Snedecor \& Cochran, 1980). The uterine tone values, \% embryo recovery rate (no. of embryos + unfertilized eggs/no. of CL) and proportion of transferrable (grades 1-3) and poor (grade 4) quality embryos collected were evaluated by $\chi^{2}$ analysis (Snedecor \& Cochran, 1980). Mean oestradiol-17 $\beta$ concentrations from Group $N$ and I cats on Day 1 of oestrus were compared using Student's $t$ test. Alterations in progesterone profiles between the 2 groups were analysed using a split-plot design with a statistical analysis systems program (SAS, Cary, NC).

\section{Results}

Oestrous behaviour, ovarian activity, uterine appearance and embryo recovery and quality

The proportion of females allowing coitus was not different between groups $(P>0.05)$, but Group $\mathrm{N}$ queens produced fewer $\mathrm{CL}$ and unovulated follicles than did their Group I counterparts (Table 1, $P<0.01$ ). Subjective uterine tone rating (Table 1) also differed $(P<0.01)$ between groups. In Group $\mathrm{N}$ cats, the uterine horns in the early luteal phase (Fig. 1a) consistently were more turgid, containing distinct segmental swellings which contrasted to the smooth, flaccid horns of Group I females (Fig. Ib).

Table 1. Reproductive characteristics of cats in Groups $\mathrm{N}$ (natural oestrus) and I (FSH-induced oestrus)

\begin{tabular}{lccccc}
\hline Group & $\begin{array}{c}\text { No. of } \\
\text { cats }\end{array}$ & $\begin{array}{c}\text { No. } \\
\text { mating }\end{array}$ & $\begin{array}{c}\text { No. of } \\
\text { CL/female } \dagger\end{array}$ & $\begin{array}{c}\text { No. of unovulated } \\
\text { follicles/female } \ddagger\end{array}$ & $\begin{array}{c}\text { Uterine } \\
\text { tone } \$\end{array}$ \\
\hline $\mathrm{N}$ & 29 & $26(90 \%)$ & $5 \cdot 3 \pm 0.5$ & $3 \cdot 7 \pm 1 \cdot 1$ & $1 \cdot 8 \pm 0 \cdot 2$ \\
$\mathrm{I}$ & 30 & $28(93 \%)$ & $9 \cdot 4 \pm 0.9^{*}$ & $13 \cdot 6 \pm 2 \cdot \mathbf{4}^{*}$ & $3 \cdot 1 \pm 0 \cdot 2^{*}$ \\
\hline
\end{tabular}

Values are means \pm s.e.m.

†Day 4 or 5 (Day 1 = first day of oestrus).

$\ddagger>2 \mathrm{~mm}$ diameter.

§Uterine tone 1 = turgid, segmentally swollen, hypertrophied to

4 = flaccid, smooth, and small diameter.

${ }^{*} P<0.01$ compared with value for Group $\mathrm{N}$ cats.

Embryo recovery rate and the mean number of embryos recovered (from females producing embryos) were not different (Table 2) between groups. However, Group N cats proportionately produced more fertilized eggs than did Group I females. Cats in Group N produced primarily morula- to blastocyst-stage embryos, while embryos from Group I females were more retarded in development (Table 2, $P<0.01$ ). Only 1 of 14 Group $\mathrm{N}$ females produced a single unfertilized egg, whereas unfertilized eggs were collected from over half $(9 / 16)$ the Group I females $(P<0.01)$. Almost $25 \%$ of oocytes collected from Group I cats were unfertilized. The proportion of embryos judged to be of transferable quality (Fig. 3) was greater in Group N than Group I females (Table 3; 


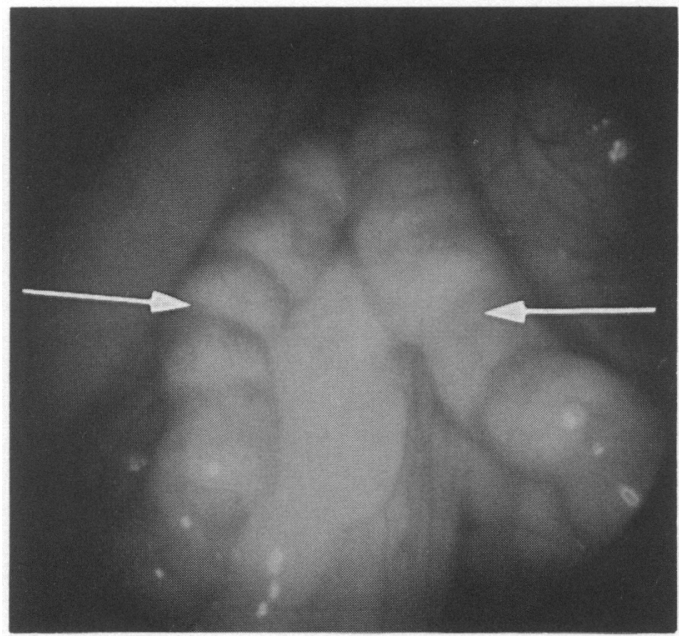

(a)

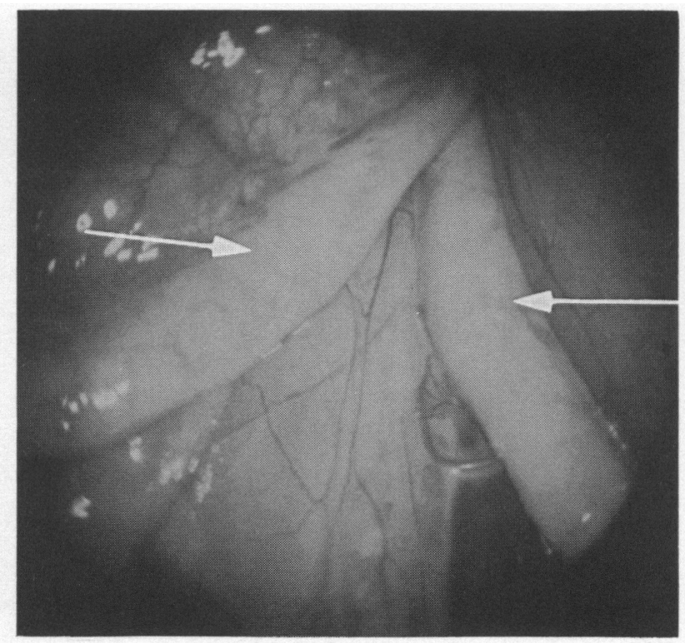

(b)

Fig. 1. Left and right uterine horns (arrows) 5 days after onset of a natural oestrus (uterine tone $=1, a$ ) or an oestrus induced with 5 daily injections of FSH (uterine tone $=4, b$ ).

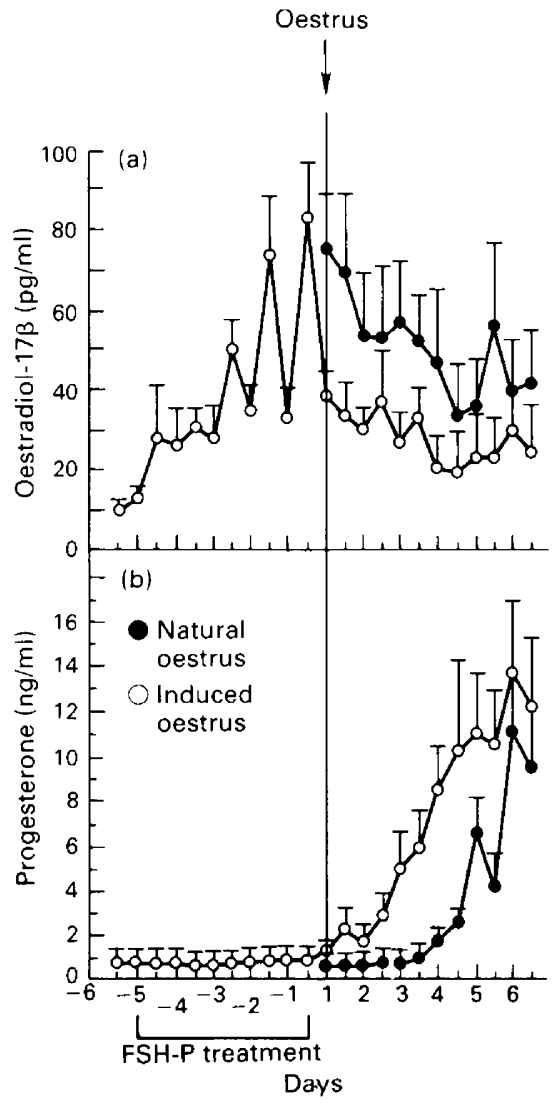

Fig. 2. Mean ( \pm s.e.m.) serum oestradiol-17ß (a) and progesterone $(b)$ profiles from domestic cats in Group $\mathrm{N}(\bullet, N=9)$ or Group I $(O, N=8)$. 

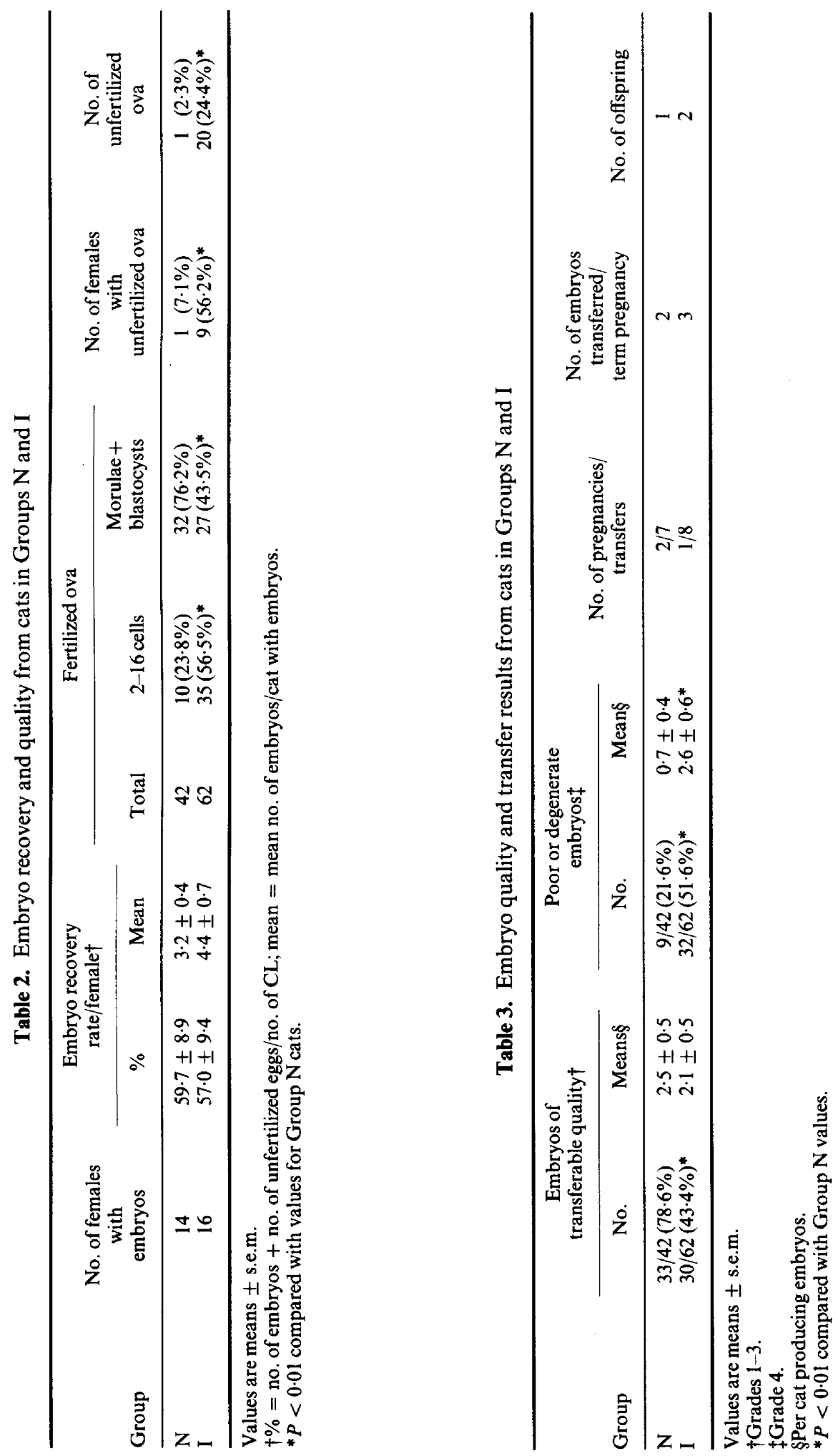


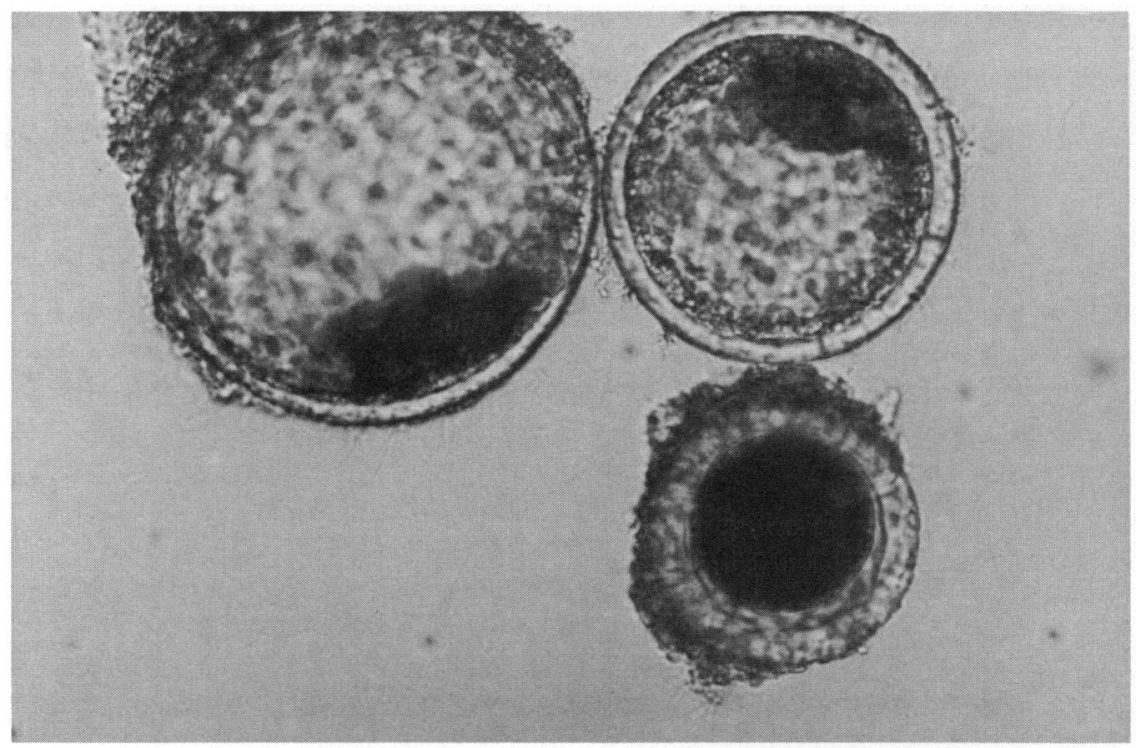

Fig. 3. An unfertilized egg and 2 blastocysts collected 8 days after onset of mating.

$P<0.01)$ while the Group I females produced a greater percentage of poor quality embryos $(P<0.01)$. Nevertheless, embryos collected from donors in Groups $\mathrm{N}$ and I and transferred into synchronized recipients resulted in pregnancies (Table 3), including the birth of 3 kittens from 2 queens. One recipient diagnosed pregnant by abdominal palpation presumably experienced fetal reabsorption.

\section{Endocrine profiles}

Although serum oestradiol-17 concentrations began to rise immediately after the onset of FSH treatment (Fig. 2a), maximal Group I values reached those in Group $N$ cats only on the afternoon of the last day of treatment (Day -1). In Group I, oestradiol-17 $\beta$ declined sharply after the cessation of gonadotrophin treatment, and by Day 1 , the mean oestradiol-17 $\beta$ concentration was 2 -fold greater $(P<0.05)$ in Group N $(72.9 \pm 13.2 \mathrm{pg} / \mathrm{ml})$ than in Group I $(36.4 \pm 5.9 \mathrm{pg} / \mathrm{ml}$; Fig. 2a). Serum progesterone remained at basal concentrations during FSH administration and rose in Group I coincident with the onset of oestrus (Day 1). In contrast, the first detectable rise in serum progesterone for Group $\mathrm{N}$ females occurred on the morning of Day $4,72 \mathrm{~h}$ after the elevation in Group I (Fig. 2b; $P<0.05$ ).

\section{Discussion}

Reports of successful embryo transfer in carnivores are available for 3 species. Experiments by Chang (1968) resulted in 1 litter of ferrets after transferring morulae and blastocysts between 2 oestrous females. Kraemer et al. (1979) performed embryo transfer in the dog by placing 37 embryos into 7 bitches 9-10 days after the first mating; 3 pregnancies and 3 litters resulted. This same laboratory also produced the first offspring from domestic cats, transferring embryos between natural oestrus donors and recipients (Kraemer et al., 1979). The present study demonstrates that successful embryo transfer is possible when ovarian activity and oestrous behaviour are induced with exogenous gonadotrophins in donor and recipient cats. However, the pregnancy rate after 
transfer is relatively low and probably can be attributed to effects of the FSH treatment on oestradiol-17 $\beta$ and progesterone concentrations.

Domestic cats appear to be highly sensitive to exogenous gonadotrophic preparations. Colby (1970) and Cline et al. (1980) administered pregnant mares' serum gonadotrophin (PMSG) and reported ovarian hyperstimulation including superovulation (as many as $60 \mathrm{CL} /$ queen) and the formation of numerous anovulatory follicles of cystic appearance ( $\geq 5 \mathrm{~mm}$ in diameter). Administration of FSH for 5 consecutive days can also cause cystic, anovulatory follicle development (Wildt et al., 1978; Goodrowe \& Wildt, 1987), and, when FSH-treated queens are artificially inseminated with fresh or frozen-thawed spermatozoa, low conception rates $(\sim 11 \%)$ result (Platz et al., 1978). In the present study, cats given FSH and then mated (donors) or treated with hCG (recipients) continued to maintain follicles of abnormal appearance during the early luteal phase.

The use of exogenous gonadotrophins for ovulation induction has been associated with reduced fertilization rates in vivo and in vitro and poor early embryonic development in the rabbit, cat, mouse, rat and sheep (Fujimoto et al., 1974; Herron \& Sis, 1974; Maudlin \& Fraser, 1977; Evans \& Armstrong, 1984a, b; Moor et al., 1985; Vanderhyden et al., 1986). These adverse effects have been attributed to the release of immature, atretic or chromosomally abnormal oocytes or altered gamete transport. Any of these factors could be responsible for the differences in embryo quality and development observed in the present study, and all could have resulted directly from an altered endocrine environment.

The temporal and quantitative oestradiol-17 $\beta$ and progesterone patterns of cats in Group $\mathrm{N}$ were comparable to those reported previously (Wildt et al., 1981a; Schmidt et al., 1983). Hormonally, queens responded rapidly to FSH treatment, the first detectable rise in oestradiol-17 $\beta$ occurring within $12 \mathrm{~h}$ of the initial injection. Subsequent elevations in oestrogen were observed in afternoon samples following repeated gonadotrophin injections. However, the continuous rise of oestradiol-17 $\beta$ over the 5-day injection period could not be sustained into behavioural oestrus, indicating that steroidogenesis within the FSH-recruited follicles was prematurely altered. The FSH preparation apparently contains significant LH-like activity (Lindsell et al., 1986) which may have induced early follicular luteinization and ovulation, thereby explaining the marked decline in circulating oestradiol$17 \beta$ coincident with the early rise in progesterone. Release of immature oocytes coupled with gamete ageing and, thus, asynchronous gamete interaction could have contributed to a reduced fertilization rate and poor embryo quality in the cats in Group $\mathrm{I}$. The altered endocrine environment also could have affected sperm transport, as observed previously in ewes inseminated vaginally after FSH treatment (Evans \& Armstrong, 1984b). Although not studied in most carnivores, sperm transport is known to be compromised in at least 1 species of wild felid (the tiger) after gonadotrophin treatment: flushing the reproductive tract of FSH-treated tigers revealed no sperm cells in the oviduct or cranial aspect of the uterine horn $1 \mathrm{~h}$ after transcervical insemination with fresh spermatozoa (Wildt et al., 1987).

It is clear that live-born domestic cat offspring can be produced from embryo transfer after gonadotrophin treatment of the donor and recipient. However, the hormone regimen used was not conducive to high pregnancy rates and a majority of the embryos from queens in natural oestrus did not produce term pregnancies, probably because recipients also were synchronized with FSH. Other felids, including the female cheetah and tiger, are also responsive to FSH treatment (Wildt et al., 1981b, 1986, 1987), but insemination of FSH-treated females with freshly collected spermatozoa has failed to produce a single pregnancy. Therefore, further studies are necessary to identify gonadotrophic strategies for producing ovarian responses and an endogenous endocrine environment which simulates that of a natural oestrus. Before these and related techniques can be applied to wildlife species, the surgical trauma associated with embryo recovery must also be addressed. Non-surgical embryo recovery techniques, commonly used in the cattle industry, will be a major prerequisite to the practical and repeatable use of embryo transfer in rare species in which invasive surgery is contraindicated. Other possibilities also deserve attention, including 
laparoscopic recovery of oocytes for in-vitro fertilization, a relatively atraumatic but complex approach for producing embryos while avoiding the problems of compromised sperm transport and sexual incompatibility (Wildt et al., 1987). At present, continued studies of the domestic cat are indicated before attempting wide-scale adaptation of any of these techniques to endangered felids.

We thank P. M. Schmidt, M. C. Schiewe and K. James for expert technical assistance and Dr Stephen O'Brien and the Genetics Section of the National Cancer Institute for providing the research animals. This project was supported by the Friends of the National Zoo, the Women's Committee of the Smithsonian Associates, Washington, DC, and the Center for New Opportunities in Animal Health Sciences (NOAHS Center).

\section{References}

Banks, D.H. \& Stabenfeldt, G. (1982) Luteinizing hormone release in the cat in response to coitus on consecutive days of estrus. Biol. Reprod. 26, 603-611.

Chang, M.C. (1968) Reciprocal insemination and egg transfer between ferrets and mink. J. exp. Zool. 168, $49-59$.

Cline, E.M., Jennings, L.L. \& Sojka, N.J. (1980) Breeding laboratory cats during artificially induced estrus. $L a b$. Anim. Sci. 30, 1003-1005.

Colby, E.D. (1970) Induced estrus and timed pregnancies in cats. Lab. Anim. Care 20, 1075-1080.

Concannon, P., Hodgson, B. \& Lein, D. (1980) Reflex LH release in estrous cats following single and multiple copulations. Biol. Reprod. 23, 111-117.

Elsden, R.P., Nelson, L.D. \& Seidel, G.E., Jr (1978) Superovulating cows with follicle stimulating hormone and pregnant mare's serum gonadotrophin. Theriogenology 9, 17-26.

Evans, G. \& Armstrong, D.T. (1984a) Reduction in fertilization rate in vitro of oocytes from immature rats induced to superovulate. J. Reprod. Fert. 70, 131-135.

Evans, G. \& Armstrong, D.T. (1984b) Reduction of sperm transport in ewes by superovulation treatments. $J$. Reprod. Fert. 70, 47-53.

Fujimoto, S., Pahlavan, N. \& Dukelow, W.R. (1974) Chromosome abnormalities in rabbit preimplantation blastocysts induced by superovulation. J. Reprod. Fert. 40, 177-181.

Glover, T.E., Watson, P.F. \& Bonney, R.C. (1985) Observations on variability in LH release and fertility during oestrus in the domestic cat (Felis catus). $J$. Reprod. Fert. 75, 145-152.

Goodrowe, K.L. \& Wildt, D.E. (1987) Ovarian response to human chorionic gonadotropin or gonadotropin releasing hormone in natural and induced-estrus cats. Theriogenology 27, 811-817.

Herron, M.A. \& Sis, R.F. (1974) Ovum transport in the cat and the effect of estrogen administration. Am.J. vet. Res. 35, 1277-1279.

Johnson, L.M. \& Gay, V.L. (1981a) Luteinizing hormone in the cat. I. Tonic secretion. Endocrinology 109, 240-246.

Johnson, L.M. \& Gay, V.L. (1981b) Luteinizing hormone in the cat. II. Mating-induced secretion. Endocrinology $109,247-252$.

Kraemer, D.C., Flow B.L., Schriver, M.D., Kinney, G.M. \& Pennycook, J.W. (1979) Embryo transfer in the nonhuman primate, feline and canine. Theriogenology $11,51-62$.

Lindsell, C.E., Rajkumar, K., Manning, A.W., Emery, S.K., Mapletoft, R.J. \& Murphy, B.D. (1986) Variability in FSH:LH ratios among batches of commercially available gonadotrophins. Theriogenology 25, 167, abstr.

Maudlin, I. \& Fraser, L.R. (1977) The effect of PMSG dose on the incidence of chromosomal anomalies in mouse embryos fertilized in vitro. J. Reprod. Fert. 50, 275-280.

Michael, R.P. (1961) Observations upon the sexual behaviour of the domestic cat (Felis catus $L$.) under laboratory conditions. Behaviour 18, 1-24.

Moor, R.M., Osborn, J.C. \& Crosby, I.M. (1985) Gonadotrophin-induced abnormalities in sheep oocytes after superovulation. J. Reprod. Fert. 74, $167-172$.

Platz, C.C., Wildt, D.E. \& Seager, S.W.J. (1978) Pregnancy in the domestic cat after artificial insemination with previously frozen spermatozoa. J. Reprod. Fert. 52, 279-282.

Schiewe, M.C., Schmidt, P.M. \& Wildt, D.E. (1987) A comparative study of mouse embryo freezepreservation including the examination of a thermoelectric freezing device. Cryobiology 24, 238-246.

Schmidt, P.M., Chakraborty, P.K. \& Wildt, D.E. (1983) Ovarian activity, circulating hormones and sexual behavior in the cat. II. Relationships during pregnancy, parturition, lactation and the postpartum estrus. Biol. Reprod. 28, 657-671.

Shille, V.M. \& Stabenfeldt, G.H. (1979) Luteal function in the domestic cat during pseudopregnancy and after treatment with prostaglandin $\mathrm{F}_{2 a}$. Biol. Reprod. 21, 1217-1223.

Shille, V.M., Lundstrom, K.E. \& Stabenfeldt, G.H. (1979) Follicular function in the domestic cat as determined by estradiol- $17 \beta$ concentrations in plasma: relation to estrous behavior and cornification of exfoliated vaginal epithelium. Biol. Reprod. 21, 953-963.

Shille, V.M., Munro, C., Farmer, S.W., Papkoff, H. \& Stabenfeldt, G.H. (1983) Ovarian and endocrine responses in the cat after coitus. J. Reprod. Fert. 68, 29-39.

Snedecor, G.W. \& Cochran, W.G. (1980) Statistical Methods. Iowa State University Press, Ames.

Vanderhyden, B.C., Rouleau, A., Walton, E.A. \& Armstrong, D.T. (1986) Increased mortality during 
early embryonic development after in-vitro fertilization of rat oocytes. J. Reprod. Fert. 77, 401-409.

Wildt, D.E. (1980) Laparoscopy in the dog and cat. In Animal Laparoscopy ch. 3, pp. 31-72. Eds R. M. Harrison \& D. E. Wildt. Williams \& Wilkins, Baltimore, MD.

Wildt, D.E. (1986) Estrous cycle control-Induction and prevention in cats. In Current Therapy in Theriogenology, pp. 808-812. Ed. D. A. Morrow. W. B. Saunders Co., Philadelphia.

Wildt, D.E., Kinney, G.M. \& Seager, S.W.J. (1978) Gonadotropin induced reproductive cyclicity in the domestic cat. Lab. Anim. Sci. 28, 301-307.

Wildt, D.E., Seager, S.W.J. \& Chakraborty, P.K. (1980) Effect of copulatory stimuli on incidence of ovulation and on serum luteinizing hormone in the cat. Endocrinology 107, 1212-1217.

Wildt, D.E., Chan, S.Y.W., Seager, S.W.J. \& Chakraborty, P.K. (1981a) Ovarian activity, circulating hormones, and sexual behavior in the cat. I.
Relationships during the coitus-induced luteal phase and the estrous period without mating. Biol. Reprod. 25, $15-28$.

Wildt, D.E., Platz, C.C., Seager, S.W.J. \& Bush, M. (1981b) Induction of ovarian activity in the cheetah (Acinonyx jubatus). Biol. Reprod. 24, 217-222.

Wildt, D.E., Schiewe, M.C., Schmidt, P.M., Goodrowe, K.L., Howard, J.G., Phillips, L.G., O'Brien, S.J. \& Bush, M. (1986) Developing animal model systems for embryo technologies in rare and endangered wildlife. Theriogenology 25, 33-5t.

Wildt, D.E., Phillips, L.G., Simmons, L.G., Goodrowe, K.L., Howard, J.G., Brown, J.L. \& Bush, M. (1987) Seminal-endocrine characteristics of the tiger and the potential for artificial breeding. In Tigers of the World: The Biology, Biopolitics, Management and Conservation of an Endangered Species pp. 255-279. Eds R. L. Tilson \& U. S. Seal. Noyes Publications, Park Ridge.

Received 26 May 1987 